\title{
An embedded multichannel telemetry unit for bone strain monitoring
}

\author{
Fahad Moiz ${ }^{1}$, Sharika Kumar ${ }^{1}$, Walter D Leon-Salas ${ }^{2 *}$ and Mark Johnson ${ }^{3}$
}

\begin{abstract}
An embedded telemetry unit for bone strain monitoring is presented. The telemetry unit is designed using commercially available components to lower design time and manufacturing costs. The unit can read up to eight strain gauges and measures $2.4 \mathrm{~cm} \times 1.3 \mathrm{~cm} \times 0.7 \mathrm{~cm}$. The unit is powered from a small Li-polymer battery that can be recharged wirelessly through tissue, making it suitable for implanted applications. The average current consumption of the telemetry unit is $1.9 \mathrm{~mA}$ while transmitting at a rate of $75 \mathrm{kps}$ and at a sampling rate of $20 \mathrm{~Hz}$. The telemetry unit also features a power-down mode to minimize its power consumption when it is not in use. The telemetry unit operates in the 915-MHz ISM radio band. The unit was tested in an ex vivo setting with an ulna bone from a mouse and in a simulated in vivo setting with a phantom tissue. Bone strain data collected ex vivo shows that the telemetry unit can measure strain with an accuracy comparable to a more expensive benchtop data acquisition system.
\end{abstract}

\section{Introduction}

Bones constantly adapt their mass and architecture in order to protect the internal soft tissue organs, provide structural support, and act as calcium reservoir. It is known that the mass and structural properties of bones adjust in proportion to changes in mechanical load, but the molecular basis of how this is accomplished is only partially understood [1]. In order to unravel the mechanisms of bone formation, scientists need to determine the mechanical load levels that trigger bone mass increase. To accomplish this task, localized bone strain levels need to be measured upon the application of a load to the bone. These types of bone biology studies can potentially lead to advances in musculoskeletal diagnostics and in the development of pharmaceutical targets enabling new paradigms and treatments for bone diseases such as osteoporosis.

In addition to its importance to bone biology studies, bone strain measurement is also of interest in orthopedic implant development and monitoring. The design of orthopedic implants requires information about the range

\footnotetext{
*Correspondence: wleonsal@purdue.edu

2 Electrical and Computer Engineering Technology Department, Purdue University, West Lafayette, IN 47907, USA

Full list of author information is available at the end of the article
}

of acting loads and resulting implant and bone deformations [2]. Knowledge of bone strain also facilitates rehabilitation monitoring and feedback as well as improved data collection in clinical studies [3]. In comparison to diagnosis using X-ray images, which only show bone callus growth, strain monitoring is more effective in guiding rehabilitation exercises, predicting implant malfunction, and allows continuous monitoring of the healing process [4].

Strain gauge sensors are typically employed to measure bone strain due to their small size, robustness, and good sensitivity of strain gauges [5]. Strain gauge sensors convert strain into electrical resistance. In a typical scenario, a strain gauge is attached to a bone [6], and an electronic sensing device is employed to read the strain gauge resistance and transmit it to a computer where it can be studied and stored. Ideally, the sensing device unit should be a small and wireless device because this would enable it to be implanted subcutaneously, thus improving its wearability, while a wireless link would allow unconstrained motion of its user.

Several efforts to develop wireless sensing or telemetric devices for bone strain monitoring have been reported [7-16]. These efforts include the design of application specific integrated circuits (ASICs) $[7,8]$ as well as solutions using commercially available electronic components [9-16]. The small size of ASICs makes them an attractive solution for an implantable telemetry unit. The drawback

\section{Springer}

(C) 2013 Moiz et al: licensee Springer. This is an Open Access article distributed under the terms of the Creative Commons Attribution License (http://creativecommons.org/licenses/by/2.0), which permits unrestricted use, distribution, and reproduction in any medium, provided the original work is properly cited. 
of an ASIC solution is its high design and fabrication costs, along with its long development time. In recent years, system-on-chip (SoC) solutions incorporating a radio transceiver, an analog-to-digital converter (ADC), and a central processing unit (CPU) in a single integrated circuit have become commercially available [17-20]. These SoC solutions provide a unique opportunity to develop lowcost and small telemetry units. In this work, we employ a SoC solution to develop an embedded telemetry unit for bone strain monitoring. The telemetry unit has a small size of $2.4 \mathrm{~cm} \times 1.3 \mathrm{~cm} \times 0.7 \mathrm{~cm}$, which allows it to be implanted subcutaneously. Besides its basic function of strain sensing, the telemetry unit presented here includes a three-axis accelerometer, an inductively coupled battery charger, and a multichannel front-end. The telemetry unit also features a low-power mode to extend battery life and can be configured wirelessly. The telemetry unit has been tested in an ex vivo setting using mouse bones. The unit has also been tested in a simulated implanted scenario using a tissue phantom. Test results validate the design approach of the embedded telemetry unit.

The rest of this paper is organized as follows: Section 2 outlines the target application, the design requirements and the circuit design of the telemetry unit. Section 3 details the radio communication protocol. Section 4 describes the design and organization of the firmware. Section 5 presents the measurements results, and Section 6 concludes the paper.

\section{Telemetry unit design}

Understanding the target application requirements allows us to specify the design specifications more precisely. Hence, below, we describe the target application of the telemetry unit. With the target application in mind, a set of design requirements will be outlined. These design requirements have been used to guide us in designing the telemetry unit hardware.

\subsection{Target application}

The target application for the telemetry unit is bone biology studies in which localized bone strain needs to be monitored under different load conditions. Bone biology scientists use this information to understand the mechanisms that regulate bone formation. Currently, our collaborators use the setup depicted in Figure 1 to carry out bone strain measurements. The setup consists of a specialized benchtop data acquisition system for strain gauge measurements (Vishay Micro-Measurement System 7000, Vishay Micro-Measurement, Wendell, NC, USA) that is connected to a dedicated computer running specialized data acquisition software (WinTest and StrainSmart ${ }^{\circ}$ ). In this setup, a mouse or other suitable small animal (the subject) is fully immobilized while a known force is applied to its ulna bone and strain readings are collected.

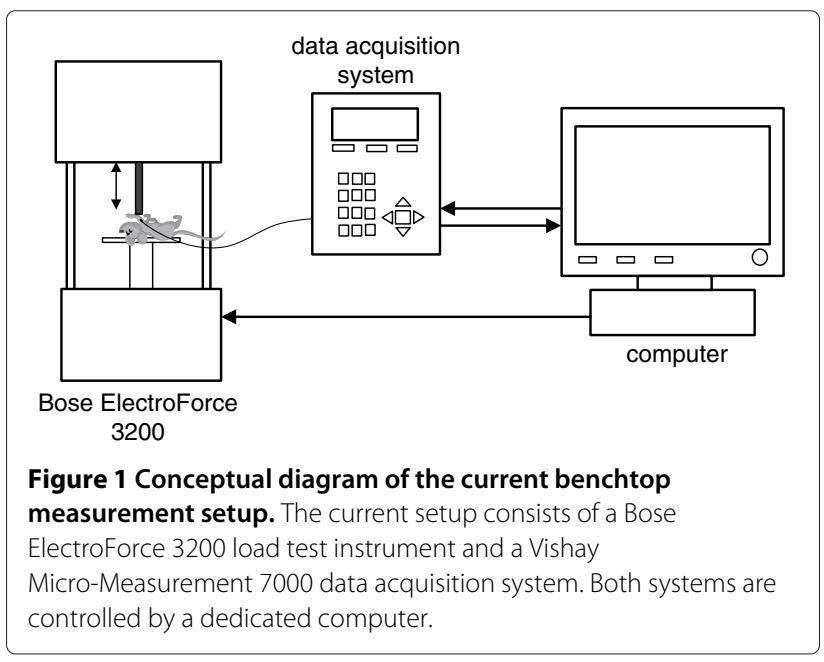

The force is applied with a Bose ElectroForce 3200 load instrument (Bose ElectroForce, Eden Prairie, MN, USA). This procedure is repeated for a period of several days after which the animal is sacrificed, and the ulna bone is studied for changes in the bone matrix and gene expression.

One important question that bone researchers would like to answer is to what degree exercise impacts bone formation. To this end, researchers would like to monitor bone strain as the subject performs a set of cage exercises. The current strain acquisition system is bulky and requires wires to be connected from the data acquisition unit to the bone. Hence, it is not suitable for use in animals that are moving during exercise. To provide a solution to this need, a wireless multichannel telemetry unit capable of reading strain is required. A conceptual diagram of the envisioned bone monitoring setup is shown in Figure 2. The telemetry unit is worn by the subject or implanted. The telemetry unit reads strain levels and transmits them to a nearby base station. The base station is connected via a cable to a computer where strain data can be plotted, analyzed, and stored.

\subsection{Design requirements}

Based on the target application, we consider the following design requirements:

- The telemetry unit should be small in size so that it can be either worn or be implanted subcutaneously in a small animal.

- The telemetry unit should have a wireless means of communication to allow unconstrained movement of the subject. Moreover, the communication range should be of $1 \mathrm{~m}$ or more to account for different cage sizes.

- The telemetry unit should have an adequate lifetime to allow researchers to take enough measurements 


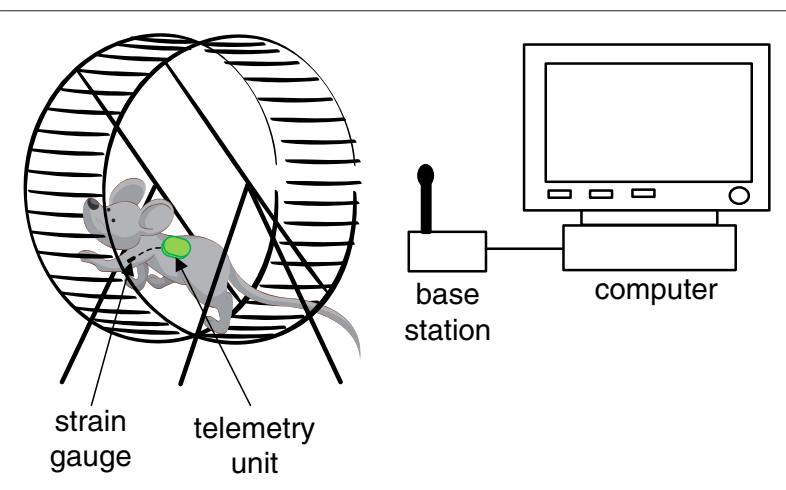

Figure 2 Conceptual diagram of a real-time wireless bone strain monitoring system. The subject is not constrained by the measurement equipment and is free to move and perform bone-growth stimulating exercises.

before replacing its batteries. It would be desirable to enable the battery to be recharged while measurements are not being taken.

- The telemetry unit should be able to read more than one strain gauge to allow strain readings to be taken at multiple bone locations.

- Since the user cannot interact directly with the telemetry unit once it is implanted, the user should be able to control the operation of the unit wirelessly. The user should be able to control parameters such as number of channels need to be read, sampling rate and duty cycle.

- A motion sensor would be desirable to have because it will allow researchers to establish the correlation between exercise and bone development.

To address the design requirements and to lower development cost and time, we decided to employ a commercially available $\mathrm{SoC}$ solution. Table 1 shows a comparison between several commercially available SoC platforms. All the selected platforms include in a single chip a microcontroller unit (MCU) and a radio transceiver. We decided to work with a radio band below $1 \mathrm{GHz}$ to minimize the attenuation of electromagnetic waves due to tissue at higher frequencies [21]. The CC430F5137 microcontroller was selected because of its superior on-chip flash and RAM memory and peripheral resources. The CC430F5137 also features a 16-bit CPU with several lowpower modes. The $915-\mathrm{MHz}$ ISM radio band was selected to communicate with the base station because it is a license free band.

Some telemetry unit designs employ radio frequency identification technology (RFID) to transmit data wirelessly $[15,16]$. The advantage of the RFID-based designs is that power is supplied to the unit by a reader. Thus, there is no need to use a battery [22]. The drawback of RFIDbased designs is that the communication range is limited to few inches and because they have low data transmission rates, which limit the sampling rate of the sensor to only few samples per second. Due to these drawbacks, RFID technology was not employed for data communications in our design.

\subsection{Strain sensing}

Strain gauges are piezoresistive sensors, that is, their resistance changes when they are stretched or compressed. The most common type of strain gauge is the metallic strain gauge, which consists of a very fine wire arranged in a grid pattern. The wire is bonded to a thin and flexible substrate, which is then attached to the test specimen. As the test specimen is deformed, the thin wire in the gauge is stretched or compressed, thus changing its length and consequently its electrical resistance [23]. Other types of strain gauges are based on semiconductor materials, like silicon. Silicon-based strain gauges are usually more sensitive than metallic gauges. However, metallic gauges tend to have better linearity [24].

The change in resistance $\Delta R$ and the strain in a strain gauge are related by the following equation:

$$
G=\frac{\Delta R}{R \times \varepsilon}
$$

where $G$ is the gauge factor, $R$ is the nominal gauge resistance, and $\varepsilon$ is the strain experienced by the gauge commonly measured in units of micro-strain $(\mu \epsilon)$.

We chose to work with the Vishay EA-06-015DJ-120 strain gauges due to their very small size and good linearity. The selected strain gauge has a nominal resistance of $120 \Omega$ and a gauge factor of $G=2.07$. The maximum bone strain that is expected in the experiments is about $3,000 \mu \epsilon$. Therefore, the maximum expected change in resistance is $0.75 \Omega$ or $0.625 \%$ of its nominal resistance. The traditional approach to measure such small resistance changes is to use a Wheatstone bridge in combination with an amplifier as shown in Figure 3a. The output of the amplifier is then converted to digital using an analogto-digital converter (ADC). In the figure, $R_{S}$ is the strain gauge resistance.

Letting $R_{S}=R+\Delta R$ and $R_{1}=R_{P}=R_{S}=R$, the following expression for $V_{\text {OUT }}$ can be obtained:

$$
V_{\mathrm{OUT}}=A \cdot V_{\mathrm{EX}}\left(\frac{\alpha}{2(2+\alpha)}\right)
$$

where $\alpha=\Delta R / R$ and $A$ is the gain of the instrumentation amplifier, which is typically set by the external resistor $R_{G}$. Considering $V_{\mathrm{EX}}=3.0 \mathrm{~V}$ and $\alpha=0.00625$, yields $V_{\mathrm{OUT}}=$ $0.0047 A$. The gain of the amplifier must be large enough to produce a voltage waveform with sufficient dynamic range so that it can be efficiently converted to digital format by 
Table 1 Comparison of several commercially available SoCs

\begin{tabular}{|c|c|c|c|c|c|c|c|}
\hline & \multicolumn{3}{|c|}{ Microcontroller unit } & \multicolumn{4}{|c|}{ Radio transceiver } \\
\hline & CPU & Memory & Peripherals & Freq. band & Modulation & Current consumption & Data rate \\
\hline \multirow[t]{4}{*}{ CC430F5137 } & 16-bit & $32 \mathrm{kB}$ flash & 12-bit ADC & 779 to & 2-FSK & $\mathrm{Rx}: 16 \mathrm{~mA}$ at & up to \\
\hline & RISC & 4kB RAM & 30 GPIOs & 928 & 2-GSK & $-100 \mathrm{dBm}$ & 500 \\
\hline & & (internal) & 2 16-bit timers & $\mathrm{MHz}$ & & Tx: $17 \mathrm{~mA}$ at & kbps \\
\hline & & & 2 UARTs, 2 SPI & & & $0 \mathrm{dBm}$ & \\
\hline \multirow[t]{4}{*}{ CC2510F32 } & 8-bit & $32 \mathrm{kB}$ flash & 12-bit ADC & 2.4 & 2-FSK & $\mathrm{Rx}: 21 \mathrm{~mA}$ at & up to \\
\hline & 8051 & 4kB RAM & $21 \mathrm{GPIOs}$ & $\mathrm{GHz}$ & GFSK & $-103 \mathrm{dBm}$ & 500 \\
\hline & & (internal) & 3 timers, 1 USB & & MSK & Tx: $26 \mathrm{~mA}$ at & kbps \\
\hline & & & 2 UARTs & & & $0 \mathrm{dBm}$ & \\
\hline \multirow[t]{4}{*}{ rfPIC12F675H } & 8-bit & $2 \mathrm{kB}$ flash & 10-bit ADC & 850 to & FSK & Rx: N.A. & up to \\
\hline & RISC & 64B RAM & 6 GPIOs & 930 & ASK & & 40 \\
\hline & & (internal) & 2 timers & $\mathrm{MHz}$ & & Tx: $6.5 \mathrm{~mA}$ at & kbps \\
\hline & & & & & & $2 \mathrm{dBm}$ & \\
\hline \multirow[t]{4}{*}{ nRF9E5 } & 8-bit & 4kB RAM & 10-bit ADC & 868 & GFSK & $\mathrm{Rx}: 13 \mathrm{~mA}$ at & up to \\
\hline & 8051 & (internal) & 8 GPIOs & 915 & & $-100 \mathrm{dBm}$ & 50 \\
\hline & & EEPROM & 3 timers & $\mathrm{MHz}$ & & Tx: $14 \mathrm{~mA}$ at & kbps \\
\hline & & (external) & 1 UART, 1 SPI & & & $-2 \mathrm{dBm}$ & \\
\hline
\end{tabular}

the ADC. The dynamic range (DR) at the output of the amplifier can be expressed as:

$$
\mathrm{DR}=20 \log \left(\frac{0.0047 A}{V_{\mathrm{LSB}}}\right) \mathrm{dB}
$$

where $V_{\mathrm{LSB}}=V_{\mathrm{DD}} / 2^{n}, V_{\mathrm{DD}}$ is the power supply and the reference voltage of the ADC, and $n$ is the ADC's bit resolution. Considering $V_{\mathrm{DD}}=3.0 \mathrm{~V}$ and $n=12$ bits, to achieve a dynamic range of $60 \mathrm{~dB}$ or more, a gain of at least 155 is needed. In our design, we employed a gain of 330 yielding a DR of $66.5 \mathrm{~dB}$.

A variable resistor $R_{2}$ is used in the Wheatstone bridge to calibrate the bridge such that $V_{O}=0$ when no strain is applied. We ruled out the possibility of using a mechanical potentiometer to implement $R_{2}$ to avoid vibrationinduced changes in its resistance. Moreover, a mechanical potentiometer needs to be manually tuned complicating the calibration of the bridge once it is implanted. Another option is to use a digital potentiometer as digital potentiometers are not affected by vibrations. However, commercially available digital potentiometers do not have enough resolution to match the expected resistance change in $R_{S}$.

To address the calibration problem, we employed a calibration approach that is based on a high-resolution digital-to-analog converter (DAC) instead of a variable resistor. The branch of the Wheatstone bridge composed by $R_{1}$ and $R_{2}$ is replaced with a DAC controlled by the microcontroller as shown in Figure $3 \mathrm{~b}$. The calibration procedure is depicted in Figure 4. The basic idea of the calibration procedure is to generate a voltage ramp with the DAC and monitor the output of the instrumentation amplifier when no load is applied to the strain gauge. Calibration is achieved when the output of the amplifier,

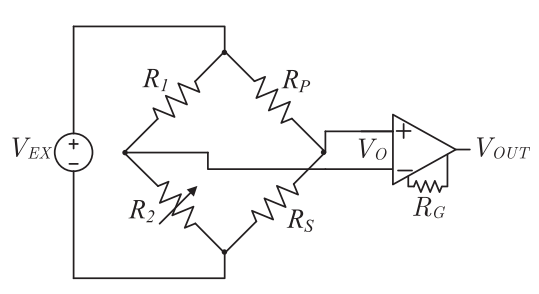

(a)

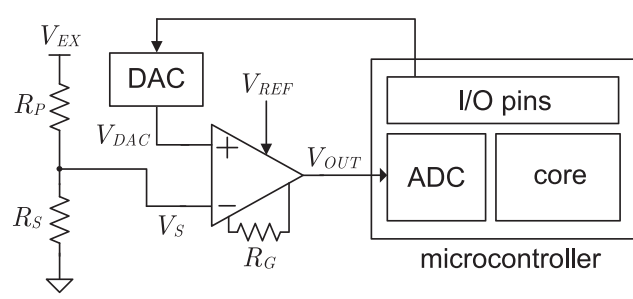

(b)

Figure 3 Resistance measurement and calibration circuits: (a) Wheatstone bridge; (b) DAC-based calibration approach. 


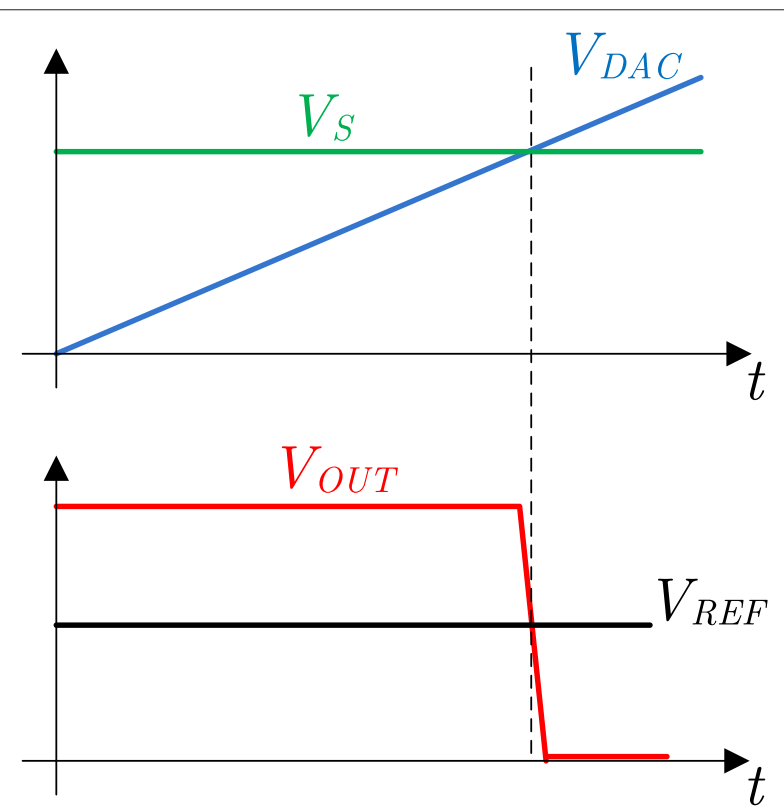

Figure 4 Calibration procedure based on a DAC and a microcontroller. The microcontroller generates a voltage ramp using a DAC until the amplifier's output equals the reference voltage $V_{\text {REF }}$.

$V_{\text {OUT }}$, equals the reference voltage $V_{\text {REF }}$. The digital input value of the DAC at the end of calibration is stored and applied in subsequent readings of the amplifier.

From Figure $3 \mathrm{~b}$, the output of the instrumentation amplifier is given by:

$$
V_{\mathrm{OUT}}=V_{\mathrm{REF}}+A\left(V_{\mathrm{DAC}}-V_{S}\right)
$$

Ideally, during calibration, we would like to set $V_{\mathrm{DAC}}=$ $V_{S}$ so that $V_{\mathrm{OUT}}=V_{\mathrm{REF}}$. In practice, the calibration procedure described above is limited by the resolution of the DAC. At the end of calibration, the maximum value of the difference $V_{\mathrm{DAC}}-V_{S}$ is $V_{\mathrm{LSB}} / 2$, where $V_{\mathrm{LSB}}=V_{\mathrm{DD}} / 2^{n}$ and $n$ is the DAC resolution. This input difference produces a maximum deviation of $A \cdot V_{\mathrm{DD}} / 2^{n+1}$ from the ideal value of $V_{\mathrm{REF}}$ at the amplifier's output. Considering a target gain of $A=330$, a supply voltage of $3.0 \mathrm{~V}$ and a 12-bit DAC resolution, the maximum output offset is 120 $\mathrm{mV}$. This offset is much smaller than the supply voltage and will not constrain the voltage swing of the amplifier's output. Thus, a DAC resolution of 12 bits is sufficient for the target application. Moreover, since the offset due to finite DAC resolution remains constant throughout the measurement process, it is canceled out digitally.

\subsection{Telemetry unit hardware}

Figure 5 shows a simplified schematic diagram of the telemetry unit which is designed around the CC430 microcontroller. An eight-channel multiplexer (MUX) is employed to allow up to eight different strain gauges to be connected to the telemetry unit. The eight-channel multiplexer comprises two low-power low-on-resistance MUXs (ADG804). A precision instrumentation amplifier $A_{1}$ (INA333) is employed to amplify the voltage difference $V_{\mathrm{DAC}}-V_{S}$. The gain of $A_{1}$ is set by the resistor $R_{G}$ according to:

$$
A_{1}=1+\frac{100 \mathrm{k} \Omega}{R_{G}}
$$

A resistor $R_{G}$ of $300 \Omega$ was employed yielding a gain of 334. The voltage $V_{S}$ is a function of the strain gauge resistance through the following voltage resistive divider relationship:

$$
V_{S}=V_{\mathrm{DD}} \frac{R_{S}}{R_{S}+R_{P}}
$$

The resistance $R_{P}$ is a precision resistor with a value matching the nominal resistance of the strain gauges. Using (5) and (6) yields the following expression for the output of the instrumentation amplifier:

$$
\begin{aligned}
& V_{\mathrm{OUT}}=V_{\mathrm{REF}}+A\left(V_{\mathrm{DAC}}-V_{S}\right) \\
& =V_{\mathrm{REF}}+\left(1+\frac{100 \mathrm{k} \Omega}{R_{G}}\right)\left(V_{\mathrm{DAC}}-\frac{V_{\mathrm{DD}} R_{S}}{R_{S}+R_{P}}\right)
\end{aligned}
$$

Thus, the amplifier's output is a function of the strain gauge resistance, $R_{S}$, which in turn is a function of the strain applied to the gauge through (1). As a result, the strain experienced by the gauge can be calculated from the voltage output of the amplifier.

The current that flows through $R_{S}$ and $R_{P}$ is given by:

$$
I_{R}=\frac{V_{\mathrm{DD}}}{R_{S}+R_{P}} .
$$

Considering $R_{S}=R_{P}=120 \Omega$ and $V_{\mathrm{DD}}=3 \mathrm{~V}$ results in a current of $12.5 \mathrm{~mA}$ flowing through the strain gauge. This current is quite large for a low-power sensor that is expected to run for long periods of time from a small battery. To reduce the average current through $R_{S}$, the resistance $R_{P}$ could be increased. However, increasing $R_{P}$ results in a reduced voltage swing across the strain gauge. To reduce current consumption without sacrificing the signal swing, the MOSFET $M_{1}$ (PMV16) is added in series with $R_{P}$ and $R_{S}$. The MOSFET works as a switch allowing current to flow through resistors $R_{P}$ and $R_{S}$ only when an analog-to-digital conversion is taking place. Otherwise, the MOSFET is turned off. Using this approach, the average current through $R_{S}$ was reduced to approximately 1 $\mathrm{mA}$.

A second DAC was added to provide a programmable voltage reference $V_{\text {REF }}$ to the instrumentation amplifier. A programmable reference level gives the flexibility of moving the amplifier's output baseline up or down to 


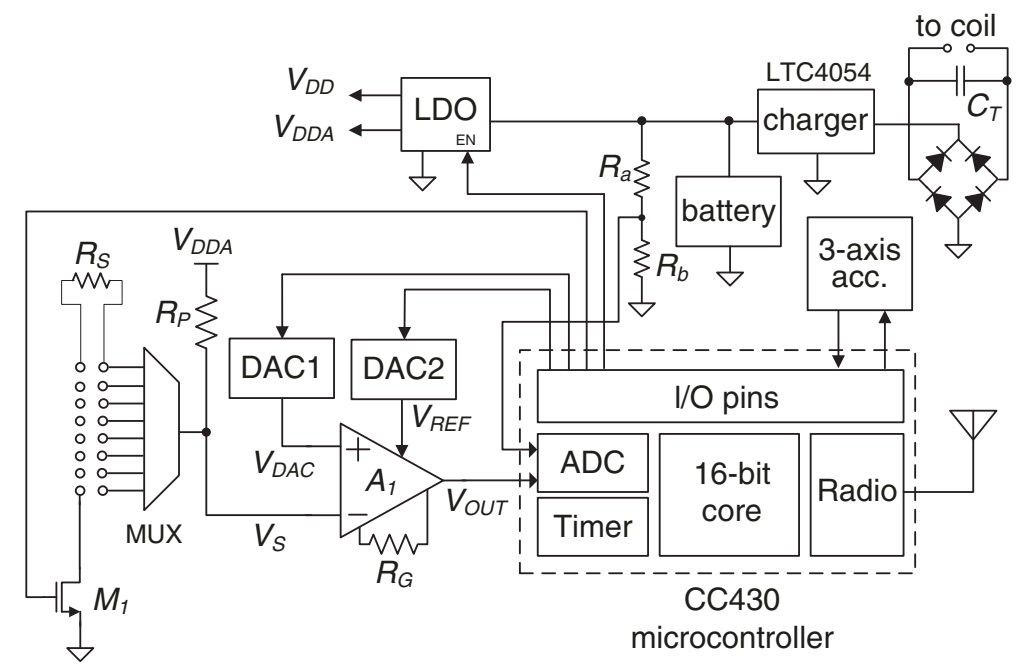

Figure 5 Schematic diagram of the telemetry unit circuit.

match the range of certain test signals such as haversines which are unidirectional. A 12-bit DAC (DAC7311) with low-power consumption and small footprint was used to implement both DAC1 and DAC2.

A three-axis accelerometer was included in the telemetry unit to enable motion information capture. The MMA8453Q accelerometer was employed due to its small size $(3 \mathrm{~mm} \times 3 \mathrm{~mm} \times 1 \mathrm{~mm})$ and very low power consumption $(0.54 \mathrm{~mW})$. The accelerometer connects to the microcontroller via a two-wire $\mathrm{I}^{2} \mathrm{C}$ bus. Motion information can be used at the sensor level to save power by triggering the transmission of strain data only when motion is detected. Furthermore, acceleration readings can be transmitted to the base station to allow researchers to establish correlations between physical exercise and bone growth. This paper focuses mainly on the acquisition and transmission of strain measurements. The transmission of acceleration readings can be accomplished with a small modification of the microcontroller's program (see Section 4).

A wireless inductive battery charger was also included on the design to enable full implantation of the unit. The charger is composed of a coil and a capacitor $C_{T}$ that form a resonant LC tank, a full-wave rectifier and the LTC4054 battery charger. A small and rechargeable lithium-polymer battery with a capacity of $45 \mathrm{mAh}$ is used to power up the telemetry unit. The voltage level of the battery is monitored by the microcontroller using the $R_{a}-R_{b}$ resistive voltage divider. The battery voltage level is sent to the base station in every transmitted radio packet. Thus, the end user can be alerted when the battery is running low and can recharge it.

The inductive charger works at a frequency of 13.5 $\mathrm{MHz}$. This frequency was chosen because it is low enough to penetrate tissue [25] and it is an unlicensed band. The resonant tank is tuned to the right frequency by varying the value of capacitor $C_{T}$. A dual output low-dropout voltage regulator (LDO) was employed to provide a stable supply voltage to the analog and digital components of the telemetry unit. The dual output LDO allows portions of the telemetry unit hardware to be powered down to reduce power consumption when the unit is signaled to enter into the SLEEP power down-mode or when the battery voltage has dropped below $3.0 \mathrm{~V}$.

In the SLEEP mode, the analog front-end (amplifier, DACs, and MUX) of the sensor as well as the accelerometer are turned off, the microcontroller is put into a low-power mode and the radio is turned off. In the SLEEP mode, the microcontroller wakes up every $3 \mathrm{~min}$, turns its radio on, transmits a status packet, and listens for possible response from the base station. If no response is received, it goes back to the SLEEP mode. On the other hand, if a response from the base station is received, the unit exits the SLEEP mode and proceeds to read and transmit data from its input channels. The SLEEP mode is designed to minimize power consumption when the unit is not being used to collect strain or motion information.

\subsection{Printed circuit board}

A four-layer printed circuit board (PCB) to host all the electronic components was designed and fabricated. The PCB with mounted components is shown in Figure 6. Special effort was made in the PCB design to minimize noise coupling into the analog signal chain. Likewise, special efforts were made to minimize the size of the board. A PCB with a size of $2.4 \mathrm{~cm} \times 1.3 \mathrm{~cm}$ was achieved. To reduce the number of discrete com- 


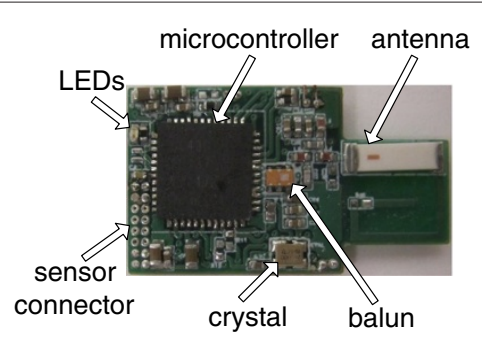

(a)

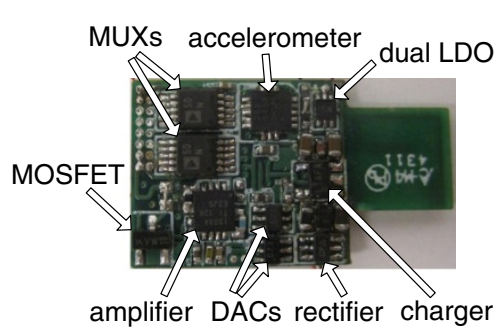

(b)

Figure 6 Photograph of the telemetry unit PCB: (a) top side; (b) bottom side.

ponents needed by the radio, a balun from Johanson Technology (0896BM15A0001) was employed in the impedance matching network. A 915-MHz chip antenna from Johanson Technology (0915AT43A0026) and a small $26 \mathrm{MHz}$ crystal oscillator were also employed to reduce board space.

Table 2 provides the cost of the electronic components in the telemetry unit. The total component cost of the telemetry unit is US\$67.11. To this cost, we should add the engineering labor time required to design and assembly the telemetry unit. The engineering labor time is estimated to be approximately $320 \mathrm{~h}$.

\section{Radio communications}

Communication between the telemetry unit and the base station is carried out using radio packets of fixed length. Each radio packet consists of a preamble, a sync word, a length field, an address field, a payload, and a 16-bit CRC. The payload has a fixed length of 60 bytes. The payload

Table 2 Cost of the electronic components in the telemetry unit

\begin{tabular}{lll}
\hline Component & Part number & Unit price (USD) \\
\hline Microcontroller & CC430F5137 & 6.75 \\
Crystal & NX2016AB-26MHZ & 1.63 \\
Balun & 0896BM15A0001E & 1.09 \\
Antenna & 0915AT43A0026 & 0.38 \\
Accelerometer & MMA8453Q & 1.43 \\
LDO & TLV7113030 & 0.64 \\
Charger & LTC4054 & 3.49 \\
Rectifier & HSMS282P & 1.71 \\
DACs & DAC7311 & $2 \times 2.32$ \\
Instrumentation amplifier & INA333 & 4.05 \\
Multiplexers & ADG804 & $2 \times 2.72$ \\
Passive components & & 2.50 \\
Four-layer PCB & & 33.36 \\
\hline Total & & 67.11 \\
\hline
\end{tabular}

field contains the information that needs to be transmitted. Depending on the type of information, a packet could be of three types: (1) a CONTROL packet, (2) a STATUS packet, and (3) a DATA packet.

A CONTROL packet is transmitted by the base station to the telemetry unit and contains commands to set parameters such as the conversion rate, the active channel number, the transmission power and whether only strain or strain and motion information are to be transmitted by the unit. A CONTROL packet is also used to signal the unit to enter or exit the SLEEP mode.

STATUS packets are transmitted by the telemetry unit to the base station only when the unit is in SLEEP mode. In SLEEP mode the telemetry unit reduces its activity by turning off its analog front end and its radio transceiver. Every $3 \mathrm{~min}$, the unit turns on its radio and transmits a STATUS packet and listens to the radio channel for $3 \mathrm{~s}$. If the unit receives a 'wake up' CONTROL packet from the base station, it exits the SLEEP mode. To differentiate between a STATUS and a DATA packet, the first 3 bytes in the STATUS payload are set to 0xFF00FF.

DATA packets are transmitted by the telemetry unit to the base station. A DATA packet is used to send strain and motion information. A DATA packet also contains calibration and sampling rate data as well as channel number and battery voltage. The format of a DATA packet's payload is shown in Figure 7. The first 6 bytes of a DATA packet contain the values of both DACs (DAC1 and DAC2), Timer A period, the active channel number, and the battery voltage. The next 54 bytes contain sensor values. A strain value has a bit length of 12 bits. Thus, a single packet can transmit 36 strain samples. Motion information is conveyed as acceleration in the $\mathrm{X}, \mathrm{Y}$, and $\mathrm{Z}$ axes. A total of 3 bytes are needed to transmit an acceleration triplet. Thus, a single packet can transmit 12 samples of strain and acceleration.

The analog-to-digital conversion rate is set by an internal timer (Timer A), and it can be changed according to the application requirements by reprogramming the timer period. Every time the Timer A finishes one counting 


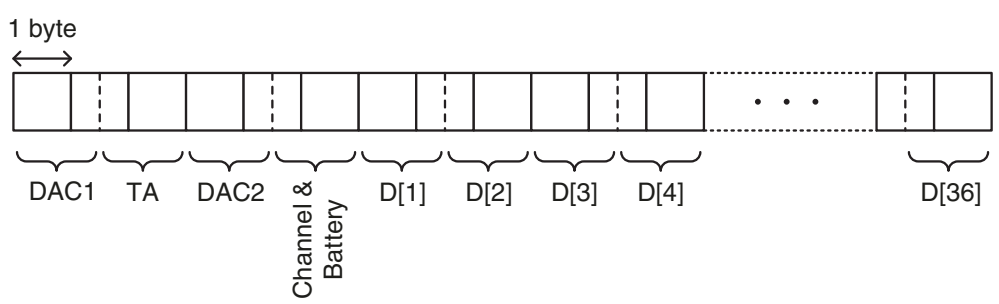

Figure 7 Format of a DATA packet's payload.

period, the ADC output is read and a new conversion is started. Hence, the conversion rate is given by:

$$
f_{\text {conv }}=\frac{f_{\text {clk }}}{\mathrm{TA}}
$$

where $f_{\text {clk }}$ is the microcontroller's clock frequency which is set to $500 \mathrm{kHz}$ and TA is the time period. Once enough samples have been collected to fill up a radio packet's payload, the packet is transmitted.

Given that it takes 36 strain samples to fill up a packet's payload, the inter-packet transmission period is equal to:

$$
T_{p}=\frac{36}{f_{\mathrm{conv}}}=\frac{36 \times \mathrm{TA}}{f_{\mathrm{clk}}}
$$

The total length of a radio packet is 576 bits including the other packet fields such as the preamble, synchronization, address, length, and CRC. Considering a radio transmission rate of $75 \mathrm{kbps}$, transmitting a radio packet takes $7.7 \mathrm{~ms}$. After the transmission of every packet, the radio transceiver is switched to reception mode for 31.2 $\mathrm{ms}$ to listen for a possible transmissions from the base station. Therefore, the minimum inter-packet transmission period, $T_{p_{\text {min }}}$, is $7.7 \mathrm{~ms}+31.2 \mathrm{~ms}=38.9 \mathrm{~ms}$. Replacing $T_{\text {pmin }}$ in (10), yields a maximum conversion rate of 925 $\mathrm{Hz}$ which divided among eight channels gives a maximum conversion rate of $115 \mathrm{~Hz}$ per channel. This sampling rate is enough for the target application. If higher sampling rates per channel are needed less number of channels would have to be scanned. The conducted ex vivo tests applied a $2-\mathrm{Hz}$ haversine force to a mouse bone. Thus, by the Nyquist theorem, the sampling rate in the ex vivo tests can be as low as $4 \mathrm{~Hz}$.

Radio transmissions are the most power-expensive operation performed by the telemetry unit. During transmission the radio transmitter consumes $17 \mathrm{~mA}$ for a power output of $0 \mathrm{dBm}$. In reception mode, the transceiver consumes $16 \mathrm{~mA}$ of current [17]. To reduce power consumption due to radio communications, the radio transceiver is turned off in between transmssions as illustrated in Figure 8. In the figure, $T_{\mathrm{x}}$ is the time required to transmit a single packet while $T_{\mathrm{rx}}$ is the listening time that follows a packet transmission. $T_{\mathrm{ff}}$ is the time during which the radio transceiver remains off. Thus, the average current consumption due to radio communications is given by:

$$
I_{\mathrm{avg}}=\frac{T_{\mathrm{tx}} I_{\mathrm{tx}}+T_{\mathrm{rx}} I_{\mathrm{rx}}}{T_{\mathrm{tx}}+T_{\mathrm{rx}}+T_{\mathrm{off}}}
$$

where, $T_{\text {off }}$ is the time the radio transceiver remains off, $T_{\mathrm{tx}}=7.7 \mathrm{~ms}, T_{\mathrm{rx}}=31.2 \mathrm{~ms}, I_{\mathrm{tx}}$ is the current consumption during transmission and $I_{\mathrm{rx}}$ is the current consumption during reception. Notice that $T_{\mathrm{tx}}+T_{\mathrm{rx}}+$ $T_{\text {off }}=T_{p}$. Replacing this result in (10) yields the following relationship:

$$
\begin{aligned}
I_{\mathrm{avg}} & =f_{\mathrm{conv}}\left(\frac{T_{\mathrm{tx}} I_{\mathrm{tx}}+T_{\mathrm{rx}} I_{\mathrm{rx}}}{36}\right) \\
& =\left(N f_{s}\right)\left(\frac{T_{\mathrm{tx}} I_{\mathrm{tx}}+T_{\mathrm{rx}} I_{\mathrm{rx}}}{36}\right),
\end{aligned}
$$

where $N$ is the number of active channels (channels being read) and $f_{\mathrm{s}}$ is the sampling rate per channel.

Thus, the average power consumption due to radio communications is directly proportional to the sampling rate per channel and to the number of channels. Figure 9 shows the average current consumption predicted by the model in (12) for a data rate of $75 \mathrm{kbps}$ and a transmission power of $0 \mathrm{dBm}\left(I_{\mathrm{tx}}=17 \mathrm{~mA}\right.$ and $\left.I_{\mathrm{rx}}=16 \mathrm{~mA}\right)$. An additional $1.5 \mathrm{~mA}$ has been added to $I_{\text {avg }}$ to account for the current consumption of the CPU, ADC, voltage regulation, and the analog signal chain (see Table 3 ).

From the battery's datasheet, we find that if $4.0 \mathrm{~mA}$ of current are continuously drawn from the battery, its voltage will drop to $3.0 \mathrm{~V}$ after approximately $12 \mathrm{~h}$. Thus, from

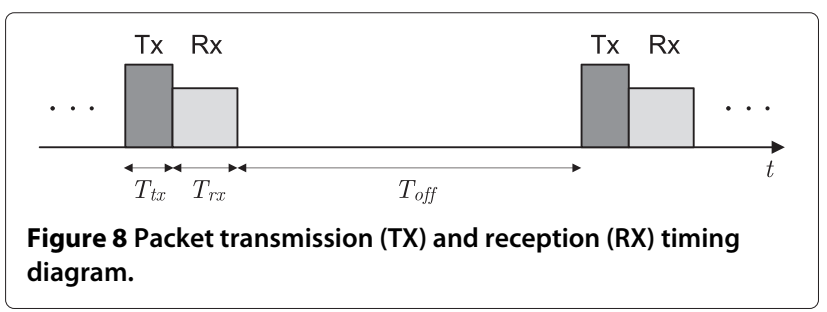




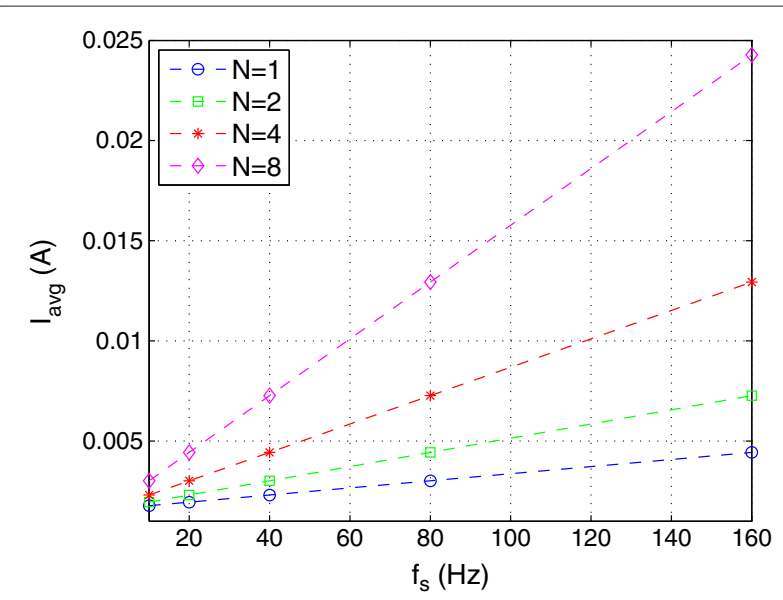

Figure 9 Average current consumption of the telemetry unit. The current consumption is a function of the number of active channels $(N)$ and the sampling rate per channel $\left(f_{s}\right)$. The data rate is $75 \mathrm{kbps}$ and a transmission output power is $0 \mathrm{dBm}$.
Figure 9, we conclude that when transmitting at $75 \mathrm{kbps}$ and $0 \mathrm{dBm}$, to collect $12 \mathrm{~h}$ of continuous data using all eight channels, the sampling rate needs to be about $18 \mathrm{~Hz}$ each. Alternatively, if only one channel is active, sampling at a rate of $33 \mathrm{~Hz}$ allows the battery to last 24 h before recharging. A typical sampling rate per channel is between 3 to $5 \mathrm{~Hz}$. Hence, the telemetry unit can run for more than $24 \mathrm{~h}$ of continuous operation.

Figure 10 shows the average current consumption when the transmission data rate is decreased to $38 \mathrm{kbps}$. At 38 kbps, the packet transmission time $T_{\mathrm{tx}}$ is $15.2 \mathrm{~ms}$. Notably, the average current consumption increases due to the increase in $T_{\mathrm{rx}}$. The advantage of using a lower transmission data rate is that the packet loss due to transmission errors decreases. Packet loss is analyzed in Section 5.3. To achieve a continuous operation of $12 \mathrm{~h}$ at $38 \mathrm{kbps}$, the sampling rate per channel should be $15 \mathrm{~Hz}$ when all eight

Table 3 Current consumption of the MCU and analog signal chain in the telemetry unit

\begin{tabular}{lll}
\hline Component & Part Number & $\begin{array}{l}\text { Current consumption } \\
(\mathbf{m A})\end{array}$ \\
\hline MCU & CC430F5137 & 0.080 \\
Accelerometer & MMA8453Q & 0.05 \\
LDO & TLV7113030 & 0.07 \\
Charger & LTC4054 & 0.025 \\
DACS & $2 \times D A C 7311$ & $2 \times 0.11$ \\
Instrumentation amplifier & INA333 & 0.05 \\
Multiplexers & 2XADG804 & $2 \times 0.004$ \\
Strain gauge & EA-06-015DJ-120 & 1 \\
Total & & 1.5 \\
\hline
\end{tabular}

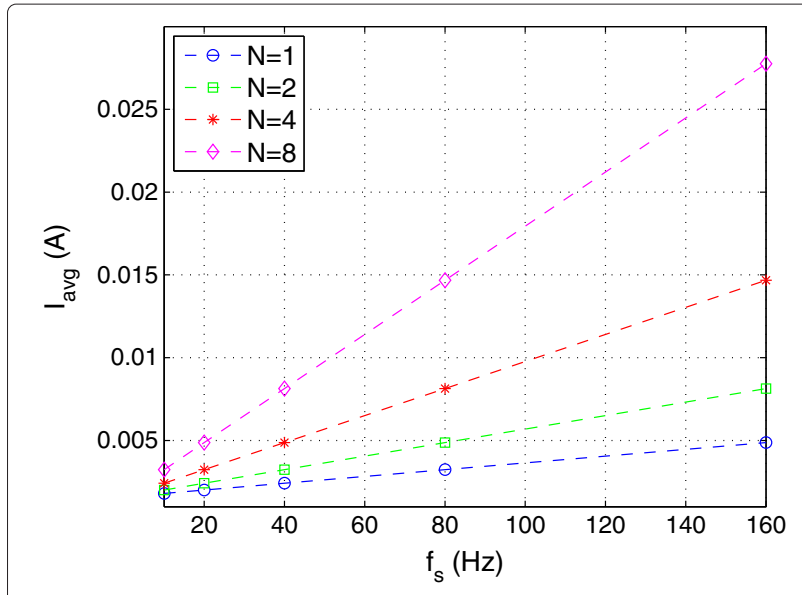

Figure 10 Average current consumption of the telemetry unit. As a function of the number of active channels $(N)$ and the sampling rate per channel $\left(f_{\mathrm{s}}\right)$. The data rate is $38 \mathrm{kbps}$ and the transmission output power is $0 \mathrm{dBm}$. channels are active. If only one channel is active, sampling it at $28 \mathrm{~Hz}$ will result in $24 \mathrm{~h}$ of continuous operation. Hence, packet loss can be traded off with battery lifetime by varying the transmission data rate.

\section{Software design}

The software design encompasses the development of three programs: one running on the telemetry unit, one running on the base station, and one running on the computer. The programs running on the telemetry unit and on the base station were written in C. The program running on the computer was written in Matlab. The program running on the telemetry unit has an interruptdriven architecture. Interrupts are employed to process information only when an event occurs. Once an interrupt request has been serviced, the $\mathrm{CPU}$ enters into a low-power mode (LPM3) to reduce power consumption. Figure 11 shows the flow diagrams of the main ( ) function (Figure 11a) and the Timer A interrupt service routine (ISR) (Figure 11b). The Timer A period changes depending on whether the unit is in SLEEP mode or not. In SLEEP mode, the timer period is $6 \mathrm{~s}$. The default timer period when the unit is not in SLEEP mode is $2.5 \mathrm{~ms}$. The timer period can be changed from the base station by transmitting a CONTROL package.

The main function of the Timer A ISR is to fill up a memory buffer (packet []) with samples from the sensors. The variable ptr is employed to keep track of how many samples have been stored in the memory buffer so far. When the memory buffer is filled (ptr = PACKET_LEN), its contents are passed to the radio transceiver and a DATA packet is transmitted. Figure 11b shows the memory buffer being filled with 


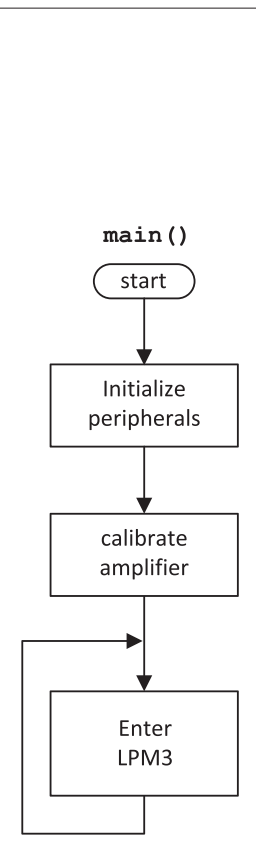

(a)

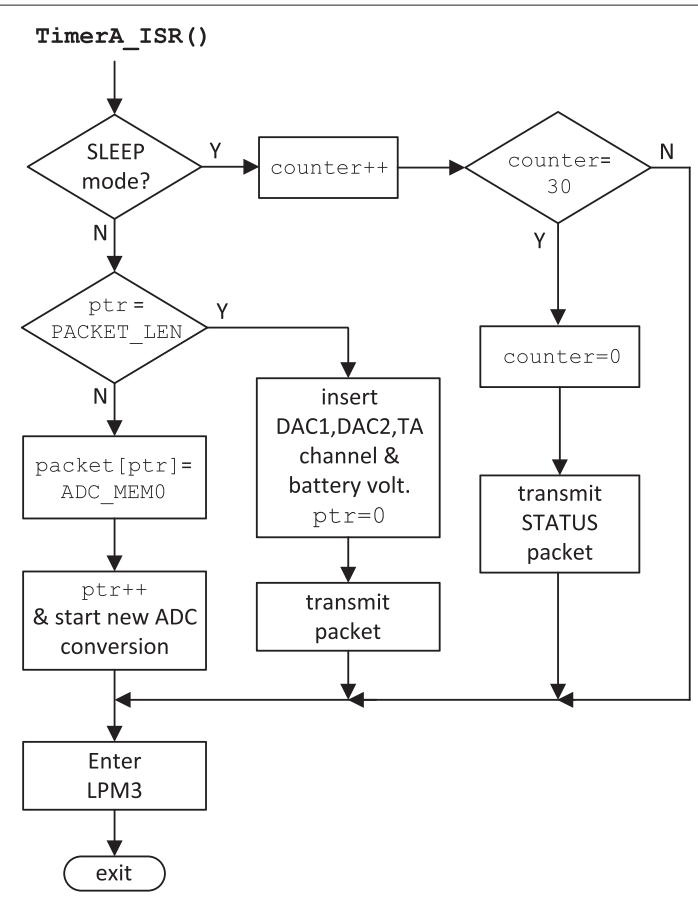

(b)

Figure 11 Flow diagram of (a) main ( ) function and (b) Timer A interrupt service routines.

readings from the ADC (strain data). To transmit acceleration data, the memory buffer should be filled with readings from the accelerometer.

Figure 12 shows the flow diagrams of the ADC ISR (Figure 12a) and the radio ISR (Figure 12b). In the radio ISR, incoming packets are checked for length and CRC. If an incoming packet has the correct length and no CRC errors, it is read into memory and decoded for possible commands from the base station.

The base station is equipped with a CC430F5137 microcontroller whose function is to receive radio packets from the telemetry unit and transmit the packets' payload contents to the computer via a FTDI serial-to-USB cable. The program in the base station also monitors how many packets are received without errors in a fixed period of time to calculate the packet loss.

Figure 13 shows a screenshot of the graphical user interface (GUI) of the program running on the computer. Using the GUI, the user can change the COM port, start and stop the display of incoming data, change the display length, save data and transmit a CONTROL packet to update the Timer A period, the DAC values, and the radio power level of the telemetry unit.

\section{Results and measurements}

The developed telemetry system was tested in an ex vivo setting and in a simulated implanted setting using a tissue phantom. The measurement results from testing the unit in both settings are presented below.

\subsection{Ex vivo test}

To perform the ex vivo test, the ulna bone of a mouse was surgically removed. A small strain gauge (Vishay EA-06-015DJ-120) was glued to the bone using M-bond 2000 from Vishay Micro-Measurements. Figure 14 shows a photograph of the ulna bone and the attached strain gage. The bone was mounted on the Bose ElectroForce 3200 load test instrument, and the strain gauge was connected to the benchtop acquisition unit. An oscillating force with a haversine shape was applied to the bone by the ElectroForce 3200 . The amplitude of the haversine was set to $3 \mathrm{~N}$ and its frequency to $2 \mathrm{~Hz}$. Strain data was collected with the StrainSmart software. The strain gauge mounted on the bone was then connected to the telemetry unit. A haversine force with the same parameters as before was applied to the bone. Strain data was collected by the telemetry unit. The sampling rate was set to $160 \mathrm{~Hz}$.

Figure 15 shows strain measurements obtained from both the benchtop acquisition system and the telemetry unit. Notably, the telemetry unit is able to acquire strain measurements with a performance comparable to the more expensive and bulkier data acquisition system. The wireless transmission from the strain gauge implanted 


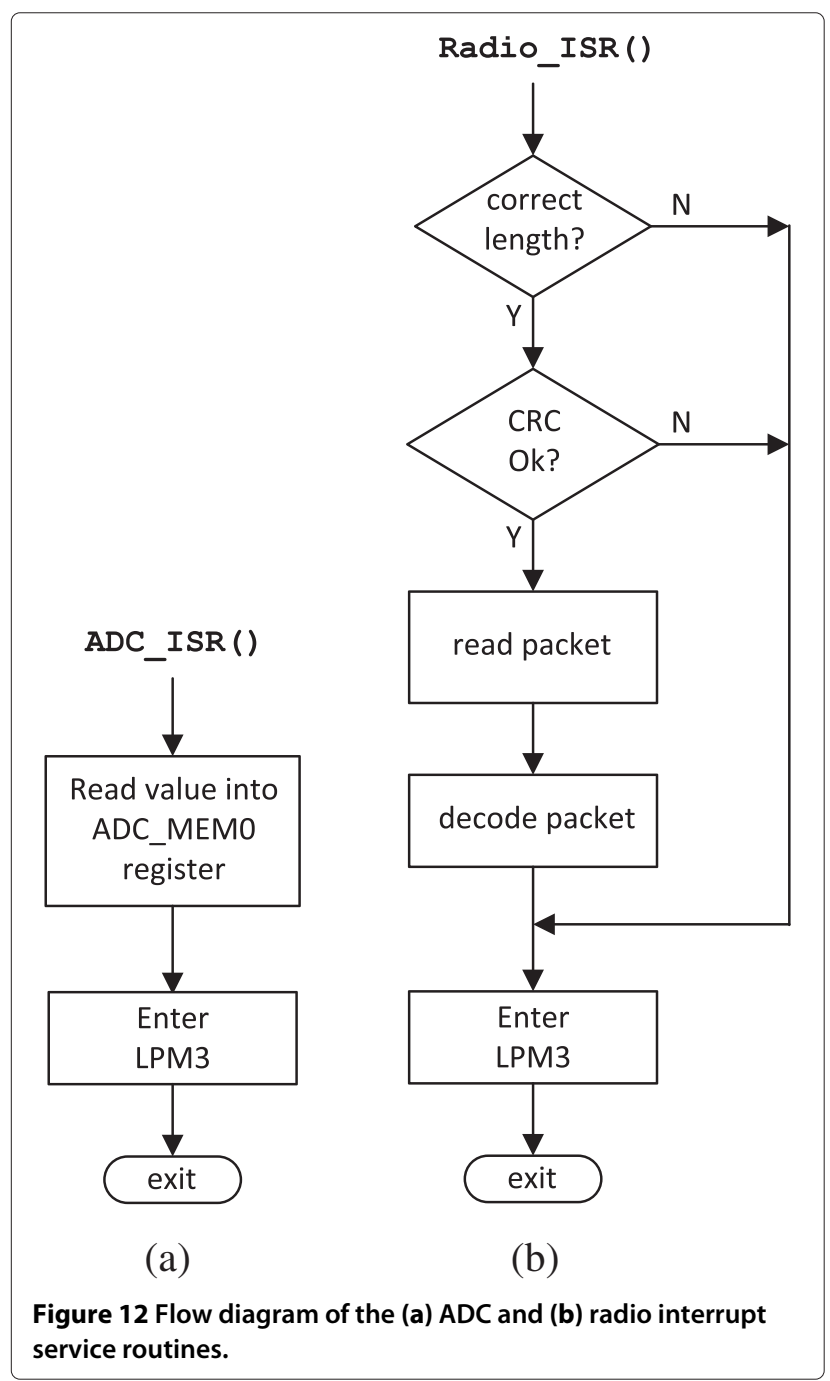

in an animal that is walking is expected to be a periodic pattern similar to the pattern shown in Figure 13 [26].

\subsection{Current consumption}

The current consumption of the telemetry unit was measured by placing a current-sense resistor of $1 \Omega$ at the input of the LDO. The voltage across the current-sense resistor was amplified with an instrumentation amplifier and read with a data acquisition board. The current drawn by the telemetry unit was calculated from the voltage readings across the current-sense resistor. Figure 16 shows the measured current consumption of the telemetry unit for different values of the sampling frequency $f_{\mathrm{s}}$ and for a single active channel. The transmission data rate was set to $75 \mathrm{kbps}$, and the transmission output power was set to $0 \mathrm{dBm}$. From the figure, it can be seen that at a sampling frequency of $10 \mathrm{~Hz}$, the current consumed by the telemetry unit is only 1.75 $\mathrm{mA}$. At a sampling frequency of $160 \mathrm{~Hz}$, the current consumption increases to $4 \mathrm{~mA}$ which is in agreement with the current consumption predicted by Equation (12) (see Figure 9). During SLEEP mode, the unit consumes $0.4 \mathrm{~mA}$.

\subsection{Tissue phantom test}

To assess the performance of the telemetry unit in an implanted scenario, a tissue phantom was created. Tissue phantoms are commonly employed to test the interaction of electromagnetic radiation and biological tissue [27]. Working with a tissue phantom has some advantages over working with cadaver animal tissue. One of the advantages is that a tissue phantom is more resistant to bacterial infection. Another advantage of a phantom

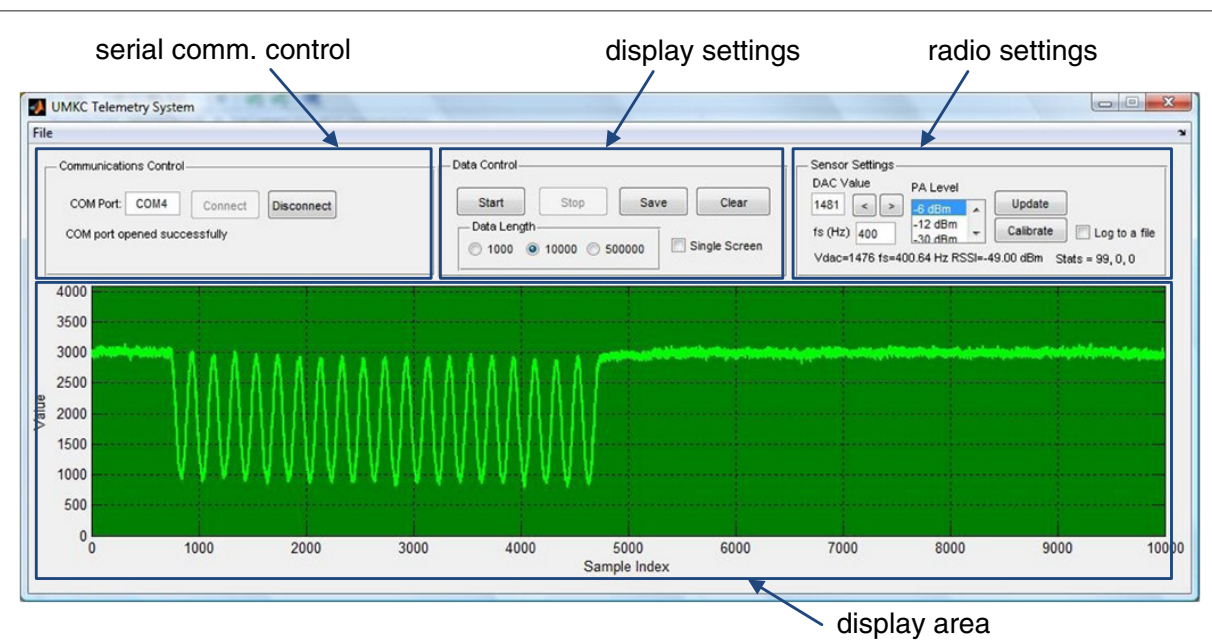

Figure 13 Screen shot of the telemetry system graphical user interface. 


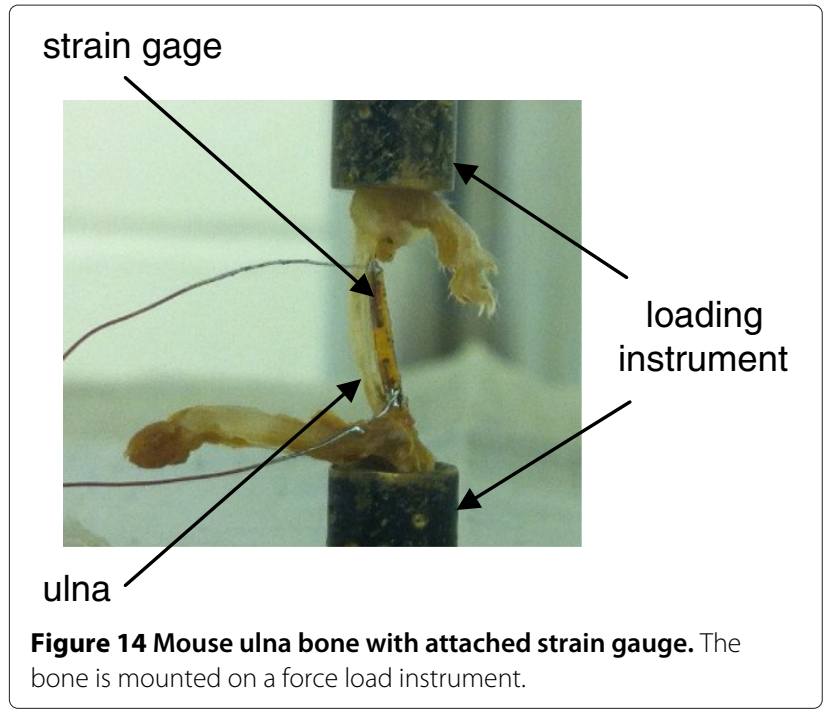

is that it does not decay and produces more consistent results than animal tissue [28].

We created a tissue phantom using gelatin and $\mathrm{NaCl}$. In $500 \mathrm{ml}$ of water, $15 \mathrm{~g}$ of gelatin was added and mixed with $1.2 \mathrm{~g}$ of $\mathrm{NaCl}$ and brought to boil [29]. The gelatin mixture was poured into a container and was allowed to solidify in a refrigerator. The telemetry unit was then placed on top of the solidified gelatin, and more gelatin mixture was then added to the container until it covered the telemetry unit by $1 \mathrm{~cm}$. The telemetry unit was previously wrapped with polymide film tape to electrically isolate the unit from the gelatin. Polymide film was employed due to its demonstrated biocompatibility properties [30]. The container was placed back in the refrigerator to allow the mixture to solidify. Figure 17 shows the telemetry unit

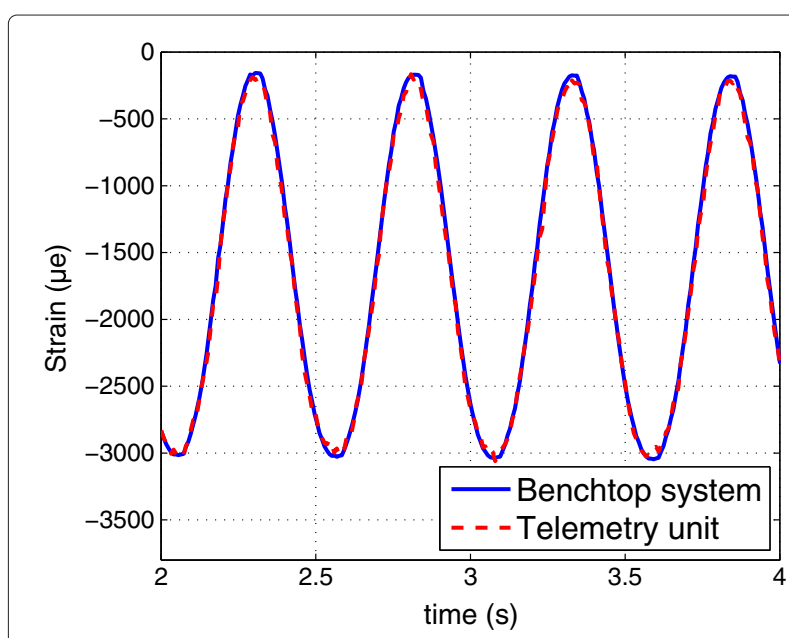

Figure 15 Strain measurements acquired with a benchtop data acquisition system and with the telemetry unit.

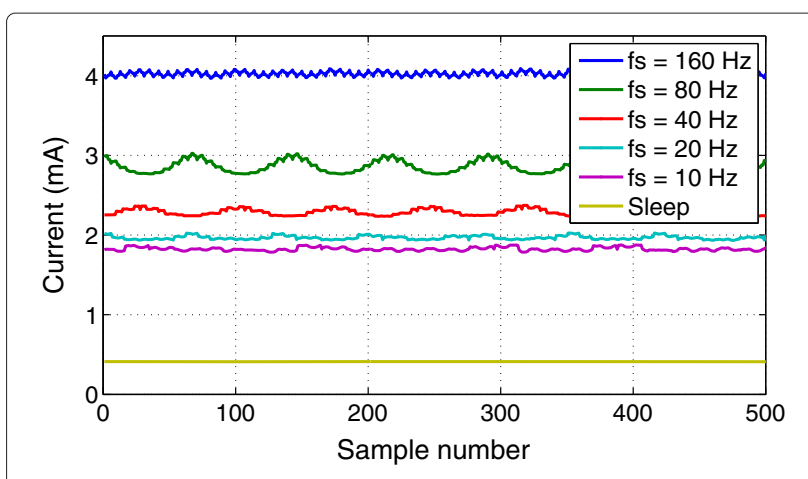

Figure 16 Current consumption of the telemetry unit for a single active channel and different sampling frequencies.

encased in the tissue phantom. Two wires were left connected to the telemetry unit to allow us to measure the battery current as the battery is recharged.

In the first test, the wireless battery charging circuit was tested. A coil of diameter of $2 \mathrm{~cm}$ and 20 turns was connected to the voltage rectifier in the telemetry unit. An external transmitter with a $1-\mathrm{W}$ power output at $13.5 \mathrm{MHz}$ and a loop antenna were employed to generate an oscillating electromagnetic field. The loop antenna was placed on top of the phantom at a distance of $1 \mathrm{~cm}$ from the coil antenna attached to the telemetry unit. The telemetry unit was place in SLEEP mode by transmitting a CONTROL packet from the base station.

The current from the charger to the battery $\left(I_{\text {batt }}\right)$ was measured using a current-sense resistor. Figure 18 shows the setup employed to measure the current $I_{\text {batt }}$. A $1-\Omega$ resistor was placed between the charger and the battery. An external instrumentation amplifier (AD620) was employed to amplify the voltage across the $1-\Omega$ resistor $\left(V_{1}-V_{2}\right)$. The gain of the instrumentation amplifier was

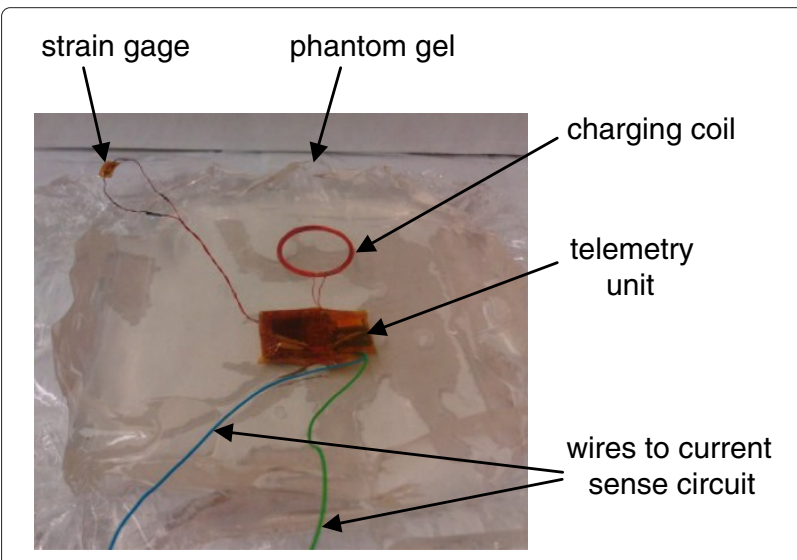

Figure 17 Telemetry unit inside tissue phantom. 


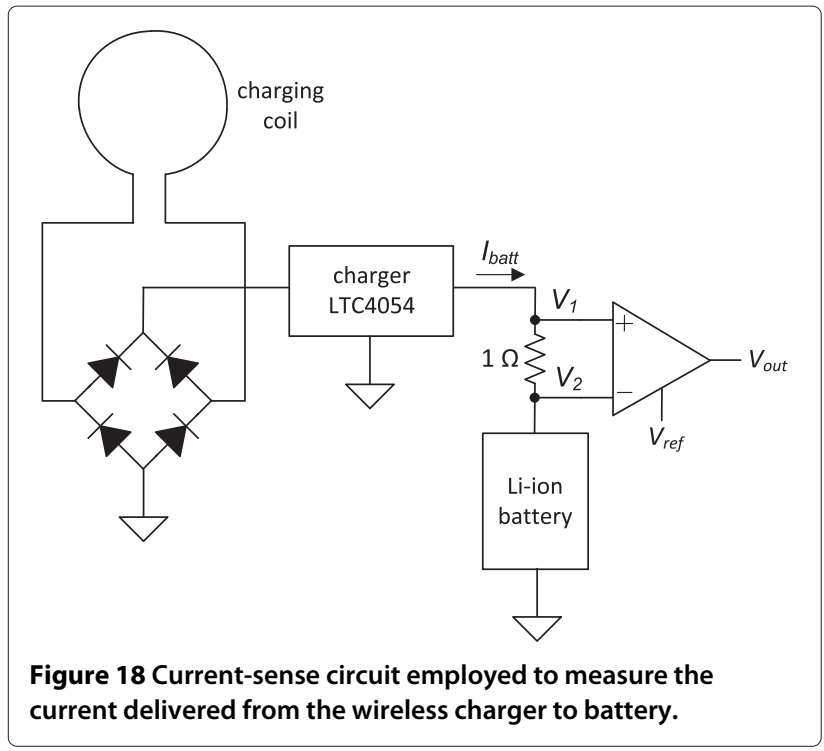

set to 100 and its reference voltage $V_{\text {ref }}$ to $1 \mathrm{~V}$. The output voltage of the instrumentation amplifier $\left(V_{\text {out }}\right)$ was read with a data acquisition board. The battery current is calculated as follows:

$$
I_{\text {batt }}=\frac{V_{\text {out }}-V_{\text {ref }}}{1 \Omega \times 100}
$$

Figure 19 shows the current delivered to the battery by the charger when the medium between the charging coil and the loop antenna is air and when it is the phantom. Figure 19 shows that the charger is able to deliver 3.4 and $1.3 \mathrm{~mA}$ to the battery when the medium air and the phantom, respectively. Hence, charging a $45-\mathrm{mA}$ fully discharged battery through the phantom will take $34 \mathrm{~h}$ approximately. However, in most practical cases, the

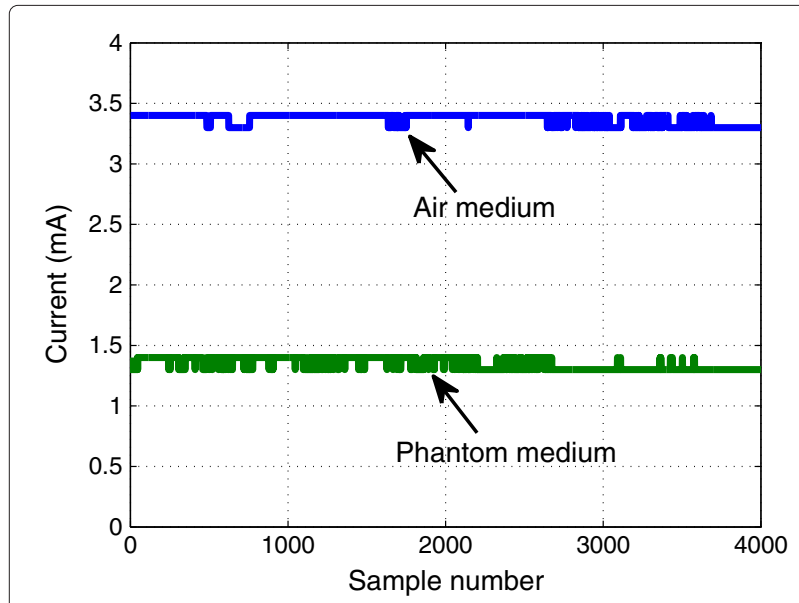

Figure 19 Current delivered to telemetry unit during wireless charging for two different mediums: air and phantom.
Table 4 Packet loss percentage for air medium and for different transmission data rates and distances

\begin{tabular}{|c|c|c|c|c|c|c|}
\hline \multirow{4}{*}{ Tx power $(\mathrm{dBm})$} & \multicolumn{6}{|c|}{ Data rate } \\
\hline & \multicolumn{3}{|c|}{38 kbps } & \multicolumn{3}{|c|}{75 kbps } \\
\hline & \multicolumn{3}{|c|}{ Distance } & \multicolumn{3}{|c|}{ Distance } \\
\hline & $50 \mathrm{~cm}$ & $1 \mathrm{~m}$ & $2 \mathrm{~m}$ & $50 \mathrm{~cm}$ & $1 \mathrm{~m}$ & $2 \mathrm{~m}$ \\
\hline 0 & $0 \%$ & $0 \%$ & $0 \%$ & $5.46 \%$ & $7.08 \%$ & $7.72 \%$ \\
\hline-12 & $0 \%$ & $0 \%$ & $1.14 \%$ & $7.82 \%$ & $9.32 \%$ & $9.8 \%$ \\
\hline-30 & $0.34 \%$ & $0.76 \%$ & $1.4 \%$ & $30.84 \%$ & $31.36 \%$ & $42.78 \%$ \\
\hline
\end{tabular}

battery is not fully discharged after one data collection session. Considering a sampling frequency of $20 \mathrm{~Hz}$ and one active channel, from Figure 16, we can see that the average current consumption is $2 \mathrm{~mA}$. Under these conditions, in a 6-h data collection session, the battery capacity is drained by $12 \mathrm{mAh}$. Using the wireless charger, it will take $9.2 \mathrm{~h}$ to replenish the charge drained by a 6 -h data collection session.

To achieve continuous operation spanning days or weeks, the current supplied by the charging coil should match or exceed the current consumption of the telemetry unit. Two strategies can be followed to achieve continuous operation. First, the current consumption of the telemetry unit can be lowered by reducing the sampling rate. However, the sampling rate cannot be made arbitrarily low to avoid introducing aliasing. Another approach to reduce current consumption is to transmit radio packets only when the accelerometer detects motion. The second strategy involves increasing the diameter and the number of turns of the charging coil so that a larger electromagnetic flux crosses the coil and induces a larger current. Alternatively, the power output of the external transmitter can be increased.

In a second test, the radio packet loss was measured. To measure packet loss, the base station counted the number of error-free packets that were received in a given amount of time. An error-free packet is a packet with the correct length and with the correct CRC. Given that the base station knows the sampling rate of the telemetry unit,

Table 5 Packet loss percentage for phantom medium and for different transmission data rates and distances

\begin{tabular}{|c|c|c|c|c|c|c|}
\hline \multirow{4}{*}{ Tx power (dBm) } & \multicolumn{6}{|c|}{ Data rate } \\
\hline & \multicolumn{3}{|c|}{38 kbps } & \multicolumn{3}{|c|}{75 kbps } \\
\hline & \multicolumn{3}{|c|}{ Distance } & \multicolumn{3}{|c|}{ Distance } \\
\hline & $50 \mathrm{~cm}$ & $1 \mathrm{~m}$ & $2 \mathrm{~m}$ & $50 \mathrm{~cm}$ & $1 \mathrm{~m}$ & $2 \mathrm{~m}$ \\
\hline 0 & $0 \%$ & $0 \%$ & $0 \%$ & $7.4 \%$ & $9.06 \%$ & $14.56 \%$ \\
\hline-12 & $0 \%$ & $0 \%$ & $1.4 \%$ & $36.04 \%$ & $39.1 \%$ & $51.66 \%$ \\
\hline-30 & $1.04 \%$ & $3.96 \%$ & $15.50 \%$ & $45.96 \%$ & $75.34 \%$ & $89.1 \%$ \\
\hline
\end{tabular}


the base station is able to calculate how many packets from the telemetry unit are expected in a given amount of time. The difference between the number of expected packets and the number of received error-free packets is the packet loss. The packet loss was measured for air and for the phantom mediums at different data rates and different distances between the telemetry unit and the base station. Tables 4 and 5 show the packet loss in percentage for these different conditions. Notably, a $0 \%$ packet loss can be achieved for a transmission data rate of $38 \mathrm{kbps}$.
If a small percentage of packet loss can be tolerated, the transmission power can be lowered to -12 or $-30 \mathrm{dBm}$ while keeping a data rate of $38 \mathrm{kbps}$.

Table 6 presents a comparison between the telemetry unit presented in this work and other embedded telemetry units for biomedical applications reported in the literature. Although it is difficult to make a one-to-one comparison since each unit was designed for a specific application, our telemetry unit compares favorably in terms of size and sensing capabilities.

Table 6 Comparison with other embedded telemetry units for biomedical applications

\begin{tabular}{|c|c|c|c|c|c|c|c|}
\hline & $\begin{array}{l}\text { Sensor } \\
\text { type }\end{array}$ & Size & Battery & $\begin{array}{l}\text { Operation } \\
\text { time }\end{array}$ & $\begin{array}{l}\text { Radio } \\
\text { band }\end{array}$ & Rechargeable & $\begin{array}{l}\text { Sampling } \\
\text { rate }\end{array}$ \\
\hline \multirow[t]{4}{*}{ This work } & Strain gage & $1.3 \mathrm{~cm}$ & Li-Po & $24 \mathrm{~h}$ & $915 \mathrm{MHz}$ & Yes & $33 \mathrm{~Hz}$ \\
\hline & (8 channels) & $\times 2.4 \mathrm{~cm}$ & $45 \mathrm{mAh}$ & & & (wireless) & \\
\hline & three-axis accel. & $\times 0.7 \mathrm{~cm}$ & & & & & \\
\hline & temperature & & & & & & \\
\hline \multirow[t]{3}{*}{ [9] } & Strain gage & $9.0 \mathrm{~cm}$ & Li-ion & $33 \mathrm{~h}$ & $2.4 \mathrm{GHz}$ & No & $617 \mathrm{~Hz}$ \\
\hline & (3 channels) & $\times 9.0 \mathrm{~cm}$ & & & & & \\
\hline & & $\times 1.8 \mathrm{~cm}$ & & & & & \\
\hline \multirow[t]{3}{*}{ [10] } & Pressure & $2.5 \mathrm{~cm}$ & Li-Po & $>4$ days & $433 \mathrm{MHz}$ & No & $1 \mathrm{~Hz}$ \\
\hline & (resistive) & $\times 5 \mathrm{~cm}$ & 850 mAh & & & & \\
\hline & & $\times 0.7 \mathrm{~cm}^{\mathrm{a}}$ & & & & & \\
\hline \multirow[t]{4}{*}{ [11] } & ECG & $2.6 \mathrm{~cm}$ & Li-Po & $>12 \mathrm{~h}$ & $2.4 \mathrm{GHz}$ & Yes & $1 \mathrm{kHz}$ \\
\hline & (3 channels) & $\times 1.5 \mathrm{~cm}$ & 40 mAh & (20\% duty & & (wired) & \\
\hline & three-axis accel. & $\times 0.7 \mathrm{~cm}$ & & cycle) & & & \\
\hline & temp., light & & & & & & \\
\hline \multirow[t]{3}{*}{ [12] } & ECG & $5.7 \mathrm{~cm}$ & Li-Po & $5 \mathrm{~h}$ & $2.4 \mathrm{GHz}$ & Yes & $1 \mathrm{KHz}$ \\
\hline & (3 channels) & $\times 3.6 \mathrm{~cm}$ & 120 mAh & (100 \% duty & & (wired) & \\
\hline & three-axis accel. & $\times 1.6 \mathrm{~cm}$ & & cycle) & & & \\
\hline \multirow[t]{3}{*}{ [13] } & Pressure \& & $1.3 \mathrm{~cm}$ & Li-Po & N. A. & $433 \mathrm{MHz}$ & Yes & N. A. \\
\hline & volume & $\times 1.3 \mathrm{~cm}$ & & & & (wireless) & \\
\hline & & $\times 1.3 \mathrm{~cm}$ & & & & & \\
\hline \multirow[t]{3}{*}{ [14] } & Pressure & $2.7 \mathrm{~cm}$ & Li coin & $56 \mathrm{~h}$ & $433 \mathrm{MHz}$ & No & $25 \mathrm{~Hz}$ \\
\hline & & $\times 1.9 \mathrm{~cm}$ & $30 \mathrm{mAh}$ & & & & \\
\hline & & $\times 1.9 \mathrm{~cm}$ & & & & & \\
\hline \multirow[t]{3}{*}{ [15] } & Pressure & $3.4 \mathrm{~cm}$ & Batteryless & Limited & $132 \mathrm{kHz}$ & Externally & $10 \mathrm{~Hz}$ \\
\hline & & $\times 1.8 \mathrm{~cm}$ & & by external & & powered & \\
\hline & & $\times 0.7 \mathrm{~cm}$ & & reader & & & \\
\hline \multirow[t]{3}{*}{ [16] } & Strain gage & $4.2 \mathrm{~cm}$ & Batteryless & Limited & $125 \mathrm{kHz}$ & Externally & $10 \mathrm{~Hz}$ \\
\hline & & $\times 0.4 \mathrm{~cm}$ & & by external & & powered & \\
\hline & & $\times 0.7 \mathrm{~cm}^{\mathrm{a}}$ & & reader & & & \\
\hline \multirow[t]{3}{*}{ [31] } & Strain gage & $3.4 \mathrm{~cm}$ & Batteryless & Limited & $2.4 \mathrm{GHz}$ & Externally & $87 \mathrm{~Hz}$ \\
\hline & & Diameter $^{a}$ & & by external & & powered & \\
\hline & & & & reader & & & \\
\hline
\end{tabular}




\subsection{Discussion}

Implanted strain gauges are typically waterproofed with different coatings to electrically isolate the gauge-wire contacts from bodily fluids and to improve the biocompatibility of the gauge. A common waterproofing technique involves coating the gauge surface with medical grade polysulfone dissolved in 1-1-2-2 tetra-chloroethane [32]. The gauge-wire junction can also be waterproofed using polymethyl-methacrylate (PMMA) followed by layers of $M$ Coat B, M Coat D, and M Coat A from Measurements Group Inc [26]. Insulated wires need to be employed to avoid contact between the metallic conductors and the bodily fluids.

To prevent infections, the strain gauge, wires, and the telemetry unit need to be sterilized before implantation, and surgery should be performed using full sterile procedures. If the telemetry unit is placed outside the body, the incision that brings the wires from the implanted strain gauge to the telemetry unit should be sealed with a tissue glue (Henry Schein, Nexaband, Melville, NY, USA) [33]. Sealing the incision prevents pathogens from entering the body and causing infection. In vivo experiments will be performed in the future with the help of a surgeon to attach the strain gauge to the ulna bone of a mouse. This type of surgery requires particular skills and equipment to ensure survival of the mouse subject.

\section{Conclusions}

An embedded multichannel strain gauge telemetry unit has been presented. The telemetry unit was designed using a commercially available SoC platform. The SoC platform employed included a CPU, memory, ADC, and a radio transceiver. The integration of all these components in a single chip allowed us to design a small telemetry unit. Furthermore, the SoC allowed us to reduce the development time and the cost. The telemetry unit operates in 915-MHz ISM radio band and measures $2.4 \mathrm{~cm} \times 1.3$ $\mathrm{cm} \times 0.7 \mathrm{~cm}$. The unit is powered from a small $45-\mathrm{mA}$ Li-polymer battery that can be recharged wirelessly through tissue making it suitable for implanted applications. The unit was tested in an ex vivo setting with an ulna bone from a mouse and in a simulated in vivo setting with a tissue phantom made in-house. Bone strain data collected by the telemetry unit were found to be in very good agreement with strain data collected by a benchtop data acquisition unit.

\section{Competing interests}

The authors declare that they have no competing interests.

\section{Acknowledgements}

The authors would like to thank the UMKC Center of Excellence for the Study of Mineralized Tissue for their support.

\section{Author details}

${ }^{1}$ Computer Science Electrical Engineering Department, University of Missouri-Kansas City, Kansas City, MO 64110, USA. ²Electrical and Computer Engineering Technology Department, Purdue University, West Lafayette, IN 47907, USA. ${ }^{3}$ Oral and Craniofacial Sciences Department, University of Missouri-Kansas City, Kansas City, MO 64108, USA.

Received: 1 July 2013 Accepted: 2 October 2013

Published: 17 October 2013

\section{References}

1. F Di Palma, M Douet, C Boachon, A Guignandon, S Peyroche, B Forest, C Alexandre, A Chamson, A Rattner, Physiological strains induce differentiation in human osteoblasts cultured on orthopaedic biomaterial. Biomaterials 24(18), 3139-3151 (2003)

2. F Burny, M Donkerwolcke, F Moulart, R Bourgois, R Puers, K Van Schuylenbergh, M Barbosa, O Paiva, F Rodes, J Bégueret, et al. Concept, design and fabrication of smart orthopedic implants. Med. Eng. Phys. 22(7), 469-479 (2000)

3. LCY Wong, WK Chiu, M Russ, S Liew, Review of techniques for monitoring the healing fracture of bones for implementation in an internally fixated pelvis. Med. Eng. Phys. 34(2), 140-152 (2012)

4. L Claes, J Cunningham, et al., Monitoring the mechanical properties of healing bone. Clin Orthop. Relat. Res. 467(8), 1964 (2009)

5. GY Yang, G Johnson, WC Tang, JH Keyak, Parylene-based strain sensors for bone. IEEE Sensors J. 7(12), 1693-1697 (2007)

6. J Cordey, E Gautier, Strain gauges used in the mechanical testing of bones Part II in vitro and in vivo technique. Injury 30, SA14-SA20 (1999)

7. Q Huang, M Oberle, A $0.5-\mathrm{mW}$ passive telemetry IC for biomedical applications. IEEE J. Solid-State Circuits 33(7), 937-946 (1998)

8. F Graichen, R Arnold, A Rohlmann, G Bergmann, Implantable 9-channel telemetry system for in-vivo load measurements with orthopedic implants. IEEE Trans. Biomed. Eng. 54(2), 253-261 (2007)

9. W De Jong, J Koolstra, L Van Ruijven, J Korfage, G Langenbach, A fully implantable telemetry system for the long-term measurement of habitual bone strain. J. Biomech. 43(3), 587-591 (2010)

10. R Tan, T McClure, C Lin, D Jea, F Dabiri, T Massey, M Sarrafzadeh, M Srivastava, C Montemagno, P Schulam, et al., Development of a fully implantable wireless pressure monitoring system. Biomed. Microdevices 11, 259-264 (2009)

11. C Park, Y Chou, PH Bai, R Matthews, A Hibbs, An ultra-wearable, wireless, low power ECG monitoring system, in IEEE Biomedical Circuits and Systems Conference (London, 29 Nov 2006-01 Dec 2006), pp. 241-244

12. V Shnayder, B Chen, K Lorincz, TRF Jones, M Welsh, Sensor networks for medical care, in International Conference On Embedded Networked Sensor Systems, vol. 2. (San Diego, 02-04 Nov 2005), pp. 314-314

13. R Sobot, Implantable RF telemetry for cardiac monitoring in the murine heart: a tutorial review. EURASIP J. Embedded Syst. 2013, 1 (2013)

14. P Valdastri, A Menciassi, A Arena, C Caccamo, P Dario, An implantable telemetry platform system for in-vivo monitoring of physiological parameters. IEEE Trans. Inf. Technol. Biomed. 8(3), 271-278 (2004)

15. J Coosemans, R Puers, An autonomous bladder pressure monitoring system. Sensors Actuators A Phys. 123, 155-161 (2005)

16. C Moss, N Weinrich, W Sass, J Mueller, Integration of a telemetric system within an intramedullary nail for monitoring of the fracture healing progress, in International Symposium on Applied Sciences in Biomedical and Communication Technologies (ISABEL) (Rome, 07-10 Nov. 2010), pp. 1-5

17. CC430F613x, CC430F612x, CC430F513x MSP430 SoC With RF Core. http://www.ti.com/lit/ds/symlink/cc430f5137.pdf. Accessed Sept. 2013

18. Low-power SoC with MCU, memory, $2.4 \mathrm{GHz}$ RF transceiver and USB controller. http://www.ti.com/lit/ds/swrs055g/swrs055g.pdf. Accessed Sept. 2013

19. Flash-based microcontroller with ASK/FSK transmitter. http://ww1. microchip.com/downloads/en/DeviceDoc/70091B.pdf. Accessed Sept. 2013

20. 433/868/915 MHz RF transceiver with embedded 8051 compatible microcontroller and 4 input, 10 bit ADC. http://www.nordicsemi.com/ eng/products/sub-1-Ghz-RF/nRF9E5. Accessed Sept. 2013

21. E Grant, Interaction of radiowaves and microwaves with biological material. Br. J. Cancer 5, 1 (1982) 
22. K Finkenzeller, RFID Handbook: Fundamentals and Applications in Contactless Smart Cards, Radio Frequency Identification and Near-Field Communication (Wiley, Chichester, West Sussex, 2010)

23. Measuring Strain with Strain Gauges. http://www.ni.com/white-paper/ 3642/en/. Accessed Sept. 2013

24. C Johnson, Process Control Instrumentation Technology (Prentice Hall, Upper Saddle River, NJ, 2006)

25. AW Astrin, L Huan-Bang, R Kohno, Standardization for body area networks. IEICE Trans. Commun. 92(2), 366-372 (2009)

26. B Rabkin, J Szivek, J Schonfeld, B Halloran, Long-term measurement of bone strain in vivo: the rat tibia. J. Biomed. Mater. Res. 58(3), 277-281 (2001)

27. TL Wonnell, PR Stauffer, JJ Langberg, Evaluation of microwave and radio frequency catheter ablation in a myocardium-equivalent phantom model. IEEE Trans. Biomed. Eng. 39(10), 1086-1095 (1992)

28. MK Chmarra, R Hansen, R Mårvik, T Lang ø, Multimodal phantom of liver tissue. Plos One 8(5), e64180 (2013)

29. C Marchal, M Nadi, A Tosser, C Roussey, ML Gaulard, Dielectric properties of gelatine phantoms used for simulations of biological tissues between 10 and $50 \mathrm{MHz}$. Int. J. Hyperthermia 5(6), 725-732 (1989)

30. PJ Rousche, DS Pellinen, DPJr Pivi, JC Williams, RJ Vetter, DR kirke, Flexible polyimide-based intracortical electrode arrays with bioactive capability. IEEE Trans. Biomed. Eng. 48(3), 361-371 (2001)

31. JL Ouellette, An updated telemetry system for reliable powering in vivo coupled to a tablet computer. PhD thesis, University of Arizona, Graduate Interdisciplinary Program in Biomedical Engineering, 2013

32. J Szivek, R Roberto, D Margolis, In vivo strain measurements from hardware and lamina during spine fusion. J. Biomed. Mater. Res. B Appl. Biomater. 75(2), 243-250

33. M Park, A Belhaj-Saif, P Cheney, Chronic recording of EMG activity from large numbers of forelimb muscles in awake macaque monkeys. J. Neurosci. Methods 96(2), 153-160 (2000)

doi:10.1186/1687-3963-2013-14

Cite this article as: Moiz et al.: An embedded multichannel telemetry unit for bone strain monitoring. EURASIP Journal on Embedded Systems 2013 2013:14.

\section{Submit your manuscript to a SpringerOpen ${ }^{\odot}$ journal and benefit from:}

- Convenient online submission

- Rigorous peer review

- Immediate publication on acceptance

- Open access: articles freely available online

- High visibility within the field

- Retaining the copyright to your article

Submit your next manuscript at $\boldsymbol{~ s p r i n g e r o p e n . c o m ~}$ 